DOI: http://dx.doi.org/10.18764/2358-4319.v10n1p125-149

\title{
Uma nova sociologia em defesa das crianças e suas infâncias
}

Fabiana Oliveira Canavieira' ${ }^{1}$

\section{RESUMO}

O artigo se apresenta como uma revisão de literatura da teoria sociológica tida como clássica, buscando estabelecer relações e destacar as contribuições dos principais fundamentos sociológicos à consolidação do campo da Sociologia da Infância, como novo paradigma teórico que têm as crianças e a infância como foco de seus estudos e atuação profissional. Sem a pretensão de se constituir como um estado da arte, faz-se um desvelamento das primeiras delimitações do novo campo teórico, ao passo que se exerce a reflexividade sociológica inspirada em Bourdieu, mas percorrendo outros sociólogos.

Palavras-chave: Sociologia da Infância; Sociologia da Educação; Educação Infantil

\section{A new sociology in defense of children and their childhoods}

\section{ABSTRACT}

The article presents a literature review of the classical sociological theory, seeking to establish relationships and highlight the contributions of the main sociological foundations to the consolidation of the field of Sociology of Childhood as a new theoretical paradigm that children and childhood are the focus of its studies and professional performance. Without intending to be a state of art, we unveil the first delimitations of the new theoretical field, while the sociological reflexivity inspired by Bourdieu is exercised, but using other sociologists equally important for the present reflection.

Keywords: Sociology of Childhood; Sociology of Education; Early Children Education.

1 Mestre em Educação pela Universidade Estadual de Campinas - UNICAMP. Doutoranda em Educação pelo Programa de Pós-Graduação em Educação da Universidade Federal do Rio Grande do Sul - UFRGS. Professora do Curso de Pedagogia da Universidade Federal do Maranhão - UFMA Email: fabicanavieira@yahoo.com.br 


\section{Una nueva sociología en defensa de los niños y sus infancias}

\section{RESUMEN}

El artículo se presenta como una revisión de la literatura de la teoría sociológica clásica, buscando establecer relaciones y poner de relieve las contribuciones de los principales fundamentos sociológicos para la consolidación del campo de la sociología de la infancia como un nuevo paradigma teórico que tienen los niños y la infancia como el foco de su estudios y desempeño profesional. Sin la pretensión de constituirse como un estado de la técnica, se trata de una presentación de los primeros límites del nuevo campo teórico, mientras lleva a cabo la reflexividad sociológica inspirado por Bourdieu, pero utilizando otros sociólogos de igual importancia a esta reflexión.

Palabras clave: Sociología de la Infancia; Sociología de la Educación; Educación infantil

\section{Introdução}

A Sociologia, durante um tempo, dedicou-se a configurar seu campo com vistas a se legitimar enquanto ciência, boa parte desse processo decorreu de seu afastamento ou diferenciação em relação às ciências naturais. Deste modo, as escolas sociológicas foram se constituindo a partir principalmente da tentativa de responder ao questionamento do que é a sociedade. Em decorrência de tal questionamento outras problemáticas surgiram, sendo vistas, nesse primeiro momento como opostas, ou seja, pensar o social não só pela ótica do coletivo, mas também pela perspectiva do indivíduo, e é dentro dessas duas perspectivas que se fundamentaram as primeiras e principais teorias sociológicas.

Anseia-se ao revisar esses fundamentos da Sociologia que tem a infância como sujeito/objeto do seu conhecimento tem sido contribuir para a construção e consolidação do campo da Sociologia da Infância, de uma maneira crítica. Para tanto, imergiu-se na Sociologia como um movimento instituínte de autodefinição, enquanto se diferencia. Buscase com tal revisão uma reflexividade, no sentido atribuído por Bourdieu de objetivar a si mesmo, de pensar-se por dentro, tentando, ao mesmo tempo, uma autocrítica e uma reconstrução, a partir do olhar que põe em suspenso o que vem se constituindo como lugar-comum dentro da 
área ou na perspectiva de Octavio lanni (1976), de uma Sociologia da Sociologia, buscando ir contra a demasiada fragmentação da área e do saber sociológico, assim como preconizava Florestan Fernandes.

Não se tem o intuito de realizar um levantamento exaustivo do movimento teórico da sociologia, nem de adentrar as profundas discussões e rivalidades das escolas e/ou correntes sociológicas, pois não se pretende uma filiação às perspectivas dicotômicas e/ou binárias de ver o mundo social, já que essas formas de apreensão e explicação dos fenômenos sociais tornam muitas vezes sua compreensão limitada, levando o pesquisador/pesquisadora a escolher entre o individual, ou coletivo; entre o subjetivo, ou objetivo; estrutura, ou ação entre o macro, ou microssociológico. Interessa desvelar as relações teóricas que dão sustentação ao paradigma da Sociologia da Infância, e problematizá-la como fundamento de uma nova/outra perspectiva de compreensão das crianças e sua infância e de seu processo educacional.

\section{Um breve esboço cartográfico das infâncias na teoria sociológica}

Por idiossincrasia, não é possível falar de Sociologia da Infância sem um mergulho na teoria sociológica. Assim, para poder analisar as condições sociais da infância e sua educação à luz das teorias sociológicas dos fundadores da área, o que a insere na ampla conjuntura dos fenômenos sociais, ensaia-se uma cartografia dos estudos da infância em sua relação com as escolas sociológicas, tendo o cuidado de não forçar uma aproximação do emergente campo da Sociologia da Infância e as grandes teorias, mas situando-a sociologicamente. Para tanto, destacam-se nas teorias sociológicas apenas os elementos conceituais necessários para discutir as concepções de infância e criança.

Pode-se dizer que as primeiras aproximações da sociologia em relação à infância advêm das discussões acerca das concepções de socialização ${ }^{2}$, pela plasticidade deste conceito, ou pelas diversas formas como o processo de socialização pode ser concebido. Diferentes teóricos

2 Não me dedicarei a aprofundar o longo debate sobre socialização, mas em apresentar um panorama de como sociólogos renomados abordam a questão e aproximam-se das discussões acerca da infância. O aprofundamento do assunto exigiria uma confrontação dos diferentes pontos de vista disciplinares da biologia, psicologia e sociologia, e uma especial atenção aos estudos de Jean Piaget (1965), em que aborda a problemática do fenômeno da socialização a partir das relações explicativas da sociologia Durkheiminiana, da biologia e da psicologia genética, tentando superar as oposições entre os pontos de vistas, e que contribui no campo da sociologia da educação e da sociologia política (DUBAR, 1997). 
dedicaram-se a explicá-la e/ou conceituá-la, como Émile Durkheim, Talcott Parsons, Max Weber, Jürgen Habermans, os Interacionistas Simbólicos entre outros, mas, aqui, só caberá enfocar um deles, no caso, Durkheim por seu pioneirismo na temática e sua relação com o campo da educação.

Poder-se-iam dedicar várias pesquisas para discorrer sobre Durkheim, sua sociologia, a criação da sociologia da educação, mas, aqui, vou me deter à sua abordagem acerca da socialização e, para tanto, é necessário relembrar sua definição de educação, em que: "[...] Para que haja educação, faz-se mister que haja, em face de uma geração de adultos, uma geração de indivíduos jovens, crianças e adolescentes; e que uma ação seja exercida pela primeira, sobre a segunda (DURKHEIM, 1978, P.38)". E chegando a seguinte fórmula:

A educação é a ação exercida, pelas gerações adultas, sobre as gerações que não se encontrem ainda preparadas para a vida social; por objeto suscitar e desenvolver, na criança, certo número de estados físicos, intelectuais e morais, reclamados pela sociedade política, no seu conjunto, o pelo meio especial a que a criança, particularmente, se destine (ibidem, p.41).

[...] do parágrafo precedente, concluí-se que a educação consiste numa socialização metódica das novas gerações (ibidem, p.41).

$\mathrm{Na}$ acepção de Durkheim, a educação existe em virtude da manutenção da sociedade, a partir da criação do ser social em cada indivíduo, justamente pela educação. Assim, cada nova geração é uma "tábula rasa" a ser moldada pela sociedade via "socialização metódica", institucionalizada com objetivos e função sociais bem definidas e pela ordem moral, "meio pela qual (a sociedade) prepara no íntimo das crianças, as condições essenciais da própria existência." (DURKHEIM, 1978, p.41). Ou seja, preencher a tábula rasa, aos poucos, em etapas.

Em Durkheim, a socialização da criança é educação moral, fornece uma consciência moral própria das sociedades moderna ao indivíduo, de integração à ordem social. A moralização infantil está vinculada ao "espírito de disciplina", assegurada pelo constrangimento, por meio de sanções, complementada por uma "ligação aos grupos sociais" e interiorizada livremente graças à "autonomia da vontade". O que quer dizer que a socialização contém, em si, uma dimensão repressiva. 
A pesquisadora brasileira Fernanda Müller que se insere no campo dos estudos sociais da infância, afirma (2008) que Durkheim associou a educação ao processo de socialização, concebendo-a não somente como a ação repetida e sucessiva das gerações adultas sobre as crianças, mas como um esforço contínuo para impor às crianças maneiras de ver, de sentir e de agir às quais elas não chegariam espontaneamente.

No entanto, o que o sociólogo não pode considerar dado seu contexto foi que as crianças e os jovens também são agentes de sua própria socialização, apreendendo o mundo social à sua maneira, interpretando-o e resignificando-o junto a seus pares - crianças e jovens da mesma idade ou de idade aproximada -, e que os grupos infantis mantêm relações sociais específicas, cujas regras também são sociais. Ideia base da concepção de socialização contemporânea, da qual se origina grande parte das preocupações da Sociologia da Infância. E não a defesa de que a criança passe a ser completa quando atinge a maturidade, e deixa de ser criança.

A teoria sociológica oferece possibilidades para se enfocar a infância de várias formas para além da socialização, principalmente quando aceita que a infância constitui uma parte permanente da estrutura social que interage com outras partes dessa estrutura, e que as meninas e os meninos desde bem pequenos são afetados pelas mesmas forças políticas, econômicas e sociais que os adultos. No entanto, cabe, antes de tudo, uma ressalva, a de que nenhum dos sociólogos clássicos da sociologia geral pensou ou pesquisou as crianças pequenas no coletivo, ou seja, na escola ou na rua e em outros espaços de convivência e vivencia da infância, tal como fez Florestan Fernandes, em 1946, em sua pesquisa com as "Trocinhas do Bom Retiro".

No diálogo entre a sociologia e os estudos sociais das infâncias, observa-se a partir de diferentes teóricos e escolas sociológicas que cada uma contribuiu de diferente forma para compreensão da pequena infância e de sua educação, tais como: os escritos de Marx, Walter Benjamin, os demais teóricos da Teoria Crítica, além de Norbert Elias e os Pós-Colonialistas. E, ainda que não tenham dedicado seus estudos à infância, nem por isso deixaram de contribuir para o entendimento da criança como sujeito histórico de direitos pertencente a: uma classe social, tempo-espaço, gênero, etnia, cultura e influenciadas pelas condições socioeconômicas. 
Na perspectiva marxiana, as crianças fazem parte da reflexão sobre as condições de vida da classe trabalhadora no contexto do capitalismo. Embora para Marx tudo devesse ser feito para tentar minimizar os efeitos negativos do capital sobre as crianças, reduzindo seu sofrimento, jamais seria possível elaborar um programa pedagógico enquanto o capitalismo não ruísse dando lugar ao Estado socialista, pois os programas capitalistas de educação seriam apenas de caráter assistencialista (NOSELLA, 2002, p. 141). Assim, Marx propõe a combinação de ensino e produção, tendo o trabalho produtivo como princípio educativo e fundamentação da pedagogia socialista. $O$ pedagogo gerador do novo homem socialista é a própria indústria, ou seja, o trabalho transforma, é o meio de transformação social da nova família, da nova escola profissional e tecnológica no lugar da escola tradicional inútil e retórica. Ou seja, a fábrica, nesta perspectiva seria a grande socializadora fazendo a socialização pelo trabalho.

Refletindo a partir das ponderações que Konder (2006) faz ao pensar o marxismo e a Sociologia da Educação, vejo ser possível pensar a infância, ou as concepções de infâncias por um olhar marxista, perguntando: a criança também não se faz a si mesma enquanto sujeito ativo, criativo que existe modificando-se e superando-se? Ela também não intervém na sua realidade objetiva (na família e no contexto das políticas públicas que têm que contemplá-la)? A superação da alienação não deve partir da pequena infância? E assim como os adultos, não se inventam a si mesmas fazendo história em condições dadas? No âmago da teoria, ao pensar o homem, aborda os atuais modos de conceber a infância.

Deste modo, na nossa compreensão, Karl Marx contribui, no mínimo, em três perspectivas, com os estudos e análises acerca das concepções de infância:

i) quando aborda a história social e os vieses ideológicos da ascensão da burguesia ao poder e o papel da família nuclear dentro do sistema capitalista, atribuindo à criança um papel dentro desta lógica;

ii) quando deixa claro o pertencimento de classe de todos os agentes sociais, inclusive as crianças. Dando margem ao que Faria (2002 e 2005), citando a italiana Bertoni Jovine (1965), chama de dupla alienação da infância, ao ser explorada nas camadas populares e privatizada nas camadas médias e altas; 
iii) quando fala na potencialidade contra-hegemônica, na dinamicidade do processo histórico, a partir de uma formação crítica, socialista, de transformação do status quo; e dos laços de solidariedade, do caráter coletivista e transgressor inerente ao homem e também às crianças.

Emoutravertentesociológica, citaremos sóduas, olnteracionismo Simbólico, de viés interpretativo com foco no indivíduo e de perspectiva microteórica, que traz contribuições metodológicas que influenciaram e influenciam os estudos da e com a primeira infância. Herbert Blumer (1969) foi o responsável pelo renascimento da teoria de George Herbert Mead (1934), descreveu a sociabilidade como construção da identidade social na e pela interação - ou comunicação (gestos e linguagem) - com os outros. Em alguns pontos aproxima-se de Max Weber e da psicologia behavorista (DUBAR, 1997). Sua ideia de socialização como construção da comunicação do (EU) como membro da comunidade que participa ativamente na sua existência e, assim, na sua mudança, soma esforços no sentido de fundamentar a concepção de que a criança é agente de seu processo de socialização.

o interaccionismo simbólico - procurou estudar os processos pelos quais se desenvolve na criança o sentido do eu (self) e do outro. Para este pensador [Mead], o jogo infantil, entendido no sentido de representação de papéis (ou brincar de faz de conta), constitui um passo essencial no processo de construção da auto-consciência da criança. Trata-se de uma actividade social que pressupõe um certo domínio da linguagem (palavras, gestos, acções) e um certo contacto com o mundo dos adultos, sobretudo dos pais. [...] deste processo fundamental decorrem duas consequências decisivas para o desenvolvimento infantil: a primeira é a experiência da alteridade, isto é, do mundo exterior, enquanto realidade distinta, a qual é, para Mead, anterior à experiência que as crianças fazem de si. A segunda relaciona-se com esta: ao fazer a experiência do outro, a criança vê-se a si mesma, isto é, 'objectiva-se' como realidade separada do mundo, torna-se um self (PINTO, 1997, p. 42, sic).

De acordo com alguns estudiosos da infância, como Montandon (2001) e Pinto (1997), o recuo do funcionalismo estruturalista e a ascensão das correntes interpretativas de inspiração fenomenológica, 
impulsionadas principalmente pelo interacionismo simbólico e a etnometodologia, prepararam terreno para a construção de uma sociologia da infância.

Fortes, na primeira metade do século XX, como teorias compreensivas e explicativas dos fenômenos sociais, as teorias deterministas como o funcionalismo, o estruturalismo e o marxismo criticadas pelos pensadores da Escola de Frankfurt, pela fenomenologia e pelos movimentos "pós-modernos", foram perdendo suas forças, ao longo da segunda metade do século. A partir daí, assistindo à progressão de correntes ditas "construcionistas" ou "construtivistas", que consideram que os atores constroem o mundo em que vivem, o que significa uma espécie de "volta ao ator", seja no sentido weberiano (significação da ação), seja no sentido de Goffman ou no de Touraine, ou mesmos na de Bourdieu com a noção de habitus (BELLONI, 2009, p.5).

\begin{abstract}
[...] concepções menos deterministas e mais "construtivistas" ou "construcionistas", vieram no decorrer do século $X X$, nuançar essas bases sociológicas da relação indivíduo/sociedade, como, por exemplo, as propostas por Habermas, Bourdieu e Giddens, entre muitos outros. Esses três autores, que estão, sem dúvida, entre os principais sociólogos do século $X X$, têm em comum o fato de dar continuidade à tradição de Durkheim e Marx, no sentido de conceder certa predominância explicativa (ou heurística) ao coletivo, aos aspectos macrossociais, ou seja, às estruturas sociais, sem deixar de procurar compreender a importância dos aspectos individuais na construção daquelas estruturas, ou seja, as dimensões subjetivas e interacionais que explicam as ações individuais e suas orientações e conteúdos legitimadores e identificatórios (ibidem., p. 9).
\end{abstract}

Se a crítica anterior centrava-se apenas na unidirecionalidade defendida pelas concepções de socialização funcionalista, tornam-se equivocadas a excessiva valorização e incorporação de uma orientação teórico-metodológica centrada apenas na perspectiva das crianças, desconsiderando sua integração na dimensão mais ampla do sistema social.

Dessa constatação, decorre um aprofundamento do debate teórico em torno da relação entre o mundo das crianças e o mundo dos adultos nos diversos processos de socialização, numa tentativa 
de superar dicotomias entre perspectivas estruturais e interacionista ou da ação, visando uma compreensão da produção e reprodução do mundo social de crianças e adultos em relação de interdependência, considerando a variedade e complexidade da infância contemporânea, tem- se a emergência da Sociologia da Infância.

\section{Por uma compreensão sociológica da infância}

Mapear um campo em construção não é tarefa fácil, dada a instabilidade de suas fronteiras. A Sociologia da Infância, de matriz anglo-saxônica e francofônica, chega ao Brasil e tem sua difusão há aproximadamente duas década, e hoje está consolidada através do crescente número de publicações e pesquisas que se filiam a ela. Entender como se deram os primeiros passos de constituição dessa nova área nos permite ter uma amostra de como ela se comporta dentro do que vem a ser os campos, o acadêmico, no âmbito do Ensino Superior, através das disciplinas, pesquisas, referenciais e Associações da área, e do campo profissional, que pode ser o mesmo espaço das universidades e faculdades, mas também, e o que mais chama atenção, o espaço das instituições de educação infantil.

Utilizar-se-á da categoria de campo ${ }^{3}$ em Bourdieu (1968) como espaço onde se estabelecem as correlações de forças entre os contrários, "o campo é antes de tudo um campo de força, de poder". Aqui, esse campo é o acadêmico, mas não só, pois gravitam em torno dele os campos intelectual e profissional, estabelecendo, assim, as diferentes delimitações que essa área ganha, e dependendo, também, dos espaços sociais e das propriedades de posições ocupadas pelos sujeitos pertencentes aos campos.

No item anterior, tentou-se esclarecer, que, não dedicava às crianças e a infância atenção enquanto tema de suas investigações e explicações, pelo menos, não enquanto membros da sociedade, merecedoras de serem estudas por si mesmas, em suas especificidades, tendo-as como seres ativos tão influenciados pelas estruturas e processos sociais quanto os adultos. A pouca atenção a que as crianças tinham direito eram como sujeitos passivos da socialização e das instituições

3 Um campo é um espaço estruturado de posições sociais e também uma estrutura de relações de poder em que a posição relativa do agente é definida pela posse de formas de capital valorizadas no campo particular (BOURDIEU,2004) 
socializadoras, como propunha Durkheim. Mas a insatisfação com a ausência de mais consenso sobre essa faixa etária; as explicações habituais (mitificadas) acerca da infância e sua vida; a invisibilidade das crianças e das temáticas da infância da agenda sociológica; a falta de discussão acerca de métodos condizentes com pesquisas que considerassem as crianças enquanto portadoras de consciência, sentimentos, ideias, desejos e expectativas, com capacidade de expressá-los, e que sejam ouvidas e levadas em conta, foram alguns dos motivos que levaram profissionais e especialistas, a se dedicaram à construção de um novo paradigma teórico-metodológico que atendesse as demandas das crianças e infâncias dentro das teorias das ciências sociais.

No contexto de reconfigurações dentro do campo da sociologia, consequentemente, suas subáreas ou campos também se mobilizam por modificações. A ascendência de campos como o da Sociologia da Família (SARACENO, 1997) e Sociologia da Adolescência ou Juventude (MANNHEIM,1968; PAIS, 1993) ganham espaço dentro da área, e com elas os temas da infância, através das relações entre as diferentes gerações intergeracionais; do papel das crianças no meio familiar; da criança e a mãe trabalhadora; das crianças, divórcios e rearranjos familiares; entre outros temas.

Dentre os campos do conhecimento que configuram esse alargado espaço social em torno da temática da infância, está a Sociologia da Educação, que durante muito tempo mesmo não tendo contribuído significativamente para a visibilidade dos sujeitos e da temática, sempre esteve na fronteira dessa discussão. A Sociologia da Educação propunha a incorporação do saber sociológico descrição e explicação do fenômeno educativo, dedicando-se há até pouco tempo às questões macro sociológicas, à apresentação do pensamento das escolas sociológicas e dos seus teóricos, sendo categoricamente caracterizada pela estrutura escolar. Também questionada por tal postura, começa a reivindicar uma especificidade com foco não só nas instituições e práticas educativas, mas nos atores sociais do processo educativo, alargando o debate em torno da pluralidade das formas de produção da sociologia, ao discutir uma Sociologia da Educação NãoEscolar, encontra resposta no pensamento de Bourdieu em que diz:

a sociologia da educação [escolar] configura seu objeto particular quando se constitui como ciência das 
relações entre a produção cultural e a reprodução social, ou seja, no momento em que se esforça por estabelecer a contribuição que o sistema de ensino oferece com vistas à reprodução da estrutura das relações de força e das relações simbólicas entre as classes, então, também é possível, por analogia propor uma sociologia da educação [não-escolar] que estude como se caracterizam os contextos educativos informais mas, sobretudo, não formais enquanto instâncias de reprodução ou mudança social (BOURDIEU, 2004, p. 295).

Com as problematizações feitas à Sociologia da Educação, ela passa a se ocupar do cotidiano das instituições educacionais, da cultura escolar, das identidades, das relações sociais dentro desses espaços, e principalmente dos agentes sociais que os ocupam e de suas representações, e não apenas de seu papel social dentro da educação e da escola. No entanto, mesmo passando das questões estruturais e estruturantes para uma abordagem interpretativa e interacional, ainda assim seu olhar tinha ou tem como foco, não a educação básica como um todo, mas sim a escola obrigatória, ou seja, as instituições e os agentes sociais a partir do Ensino Fundamental. É difícil encontrar uma publicação de Sociologia da Educação que mencione a Educação Infantil, a infância, e muito menos a pequena infância, todavia, quando o fazem, recorrem ao conceito de socialização.

Não sendo esses motivos suficientes para o surgimento de um novo campo teórico, pode-se dar destaque, ainda, à necessidade de desconstrução e análise crítica dos conceitos dominantes de criança/ infância oriundos da Psicologia ${ }^{4}$ e da Biologia, principalmente da noção de desenvolvimento, que não levavam em consideração os fatores históricos e sociais que afetam as crianças.

Nesta linha, Dias (2005) faz reflexões que questionam sua profissão e identidade profissional, ao tentar entender as criticas feitas atualmente à Psicologia pela área da Educação. Ao colocar a "Psicologia no banco dos réus" em sua dissertação, ela destaca como "autos do processo": a influência do positivismo sobre esta disciplina, que no processo de se consolidar enquanto ciência recorre aos métodos

4 Sobre as críticas a hegemonia da Psicologia nos estudos da infância, ver também DAHLBERG, Gunila; MOSS, Peter; PENCE, Alan. Qualidade na educação da primeira infância: perspectivas pós-modernas. Porto Alegre: Artmed, 2003. 
objetivos das ciências naturais por meio da utilização de experimentos laboratoriais e testes psicológicos; destaca também o impacto das ideias evolucionistas na compreensão do desenvolvimento dos indivíduos, como uma analogia ao desenvolvimento das espécies, determinante nas concepções da Psicologia do Desenvolvimento, que, ao estudar as crianças, têm os adultos como referência do grau mais elevado dentro da escala evolutiva - dando destaque às faltas e incompletudes do ser infantil - e tendo este desenvolvimento como etapas que se sucedem naturalmente e universalmente.

\begin{abstract}
A criança coisificada, partida, descontextualizada, gerada pela psicologia em nome de uma pretensa naturalidade científica, é um objeto fácil de manipulação, em nome de interesses econômicos dos grupos que detêm o poder; atesta esta verdade a criança-marionete dos programas de modificação de comportamento, dos programas de educação compensatória, das baterias de testes psicológicos, todos baseados em concepções ideológicas a respeito do ambiente social, dos vínculos existentes entre as agências socializadoras e a sociedade e das relações entre os homens que vigoram numa sociedade de classes (COPIT e PATTO, 1979, apud DIAS, 2005, p.13).
\end{abstract}

No entanto, passado quase vinte anos de construção e consolidação do campo da Sociologia da Infância, seus estudiosos retomam a discussão em torno da relação entre Sociologia e Psicologia nos estudos das infâncias, reconsiderando a importância da Psicologia nessa temática (PROUT, s/d). Confirmando, essa discussão e as contradições inerentes a ela como salutares para área.

Assim, dada importância dos campos da Sociologia da Educação, da Família, da Juventude e também da Psicologia para os estudos sociais das infâncias, muitas questões ainda poderiam e podem ser exploradas no que concerne à relação destes campos com a Sociologia da Infância. Acreditando que com essa preleção pondera-se a necessidade de construção de uma nova área, e também, do por que não filiar tais discussões à Sociologia da Educação, cabe, agora, apresentar como o campo da Sociologia da Infância se constitui. Para tanto, recorre-se à simplicidade complexa dada por Roger Bastide, no prefácio da obra de Florestan Fernandes (2004, p.154), para introduzir na Sociologia da Infância, quando ele afirma: "[...] para poder estudar a criança é preciso 
tornar-se criança. Quero com isso dizer que não basta prestar-se a seus brinquedos; é preciso penetrar; além do círculo mágico que dela nos separa, em suas preocupações, suas paixões, é preciso viver o brinquedo".

Sendo assim, vale percorrer os passos daqueles que buscaram penetrar além do círculo mágico. Retome-se, então, antropofagicamente, algumas ideias importantes dos balanços bibliográficos do hemisfério norte acerca da emergência do campo da Sociologia da Infância (SIROTA, 2001), (MONTANDON, 2001), (PLAISANCE, 2004), (PROUT, s/d), (SARMENTO, 2008).

Sociologia da infância: infâncias e crianças sujeitos e objetos da pesquisa sociológica

A Sociologia da Infância, campo de estudos que vem se consolidando na arena científica internacional desde os anos 80, nasceu, no plano teórico, no movimento chamado 'retorno do ator' à cenas das Ciências Sociais em fins dos anos 60 e, plano empírico, no contexto da entrada da infância na atual agenda da opinião e política pública (MARCHI, 2009, p. 240).

No cenário da Europa do norte, o novo paradigma de estudos sociais da infância é formulado tendo como contribuição o projeto de cooperação entre dezesseis países, coordenado pelo sociólogo norueguês Jens Qvortrup, intitulado Childhood as social phenomenon (1987 - 1992), dirigido pelo European Center for Social Walfae Policy and Research de Viena, que faz uma descrição das condições sociais da infância, a partir do lugar da criança na divisão do trabalho como consequência da industrialização, levando à escolarização em massa e a mudanças no valor da infância. O projeto realizado com base numa abordagem especificamente sociológica e de cunho socioestrutural constitui a pedra fundamental da Nova Sociologia da Infância ${ }^{5}$.

Esse projeto resultou em várias publicações, mas não só, principalmente nos primeiros acontecimentos que marcam 0 reconhecimento do lugar da infância no campo sociológico, como

5 A designação"Nova Sociologia da Infância” é usada para se referir aos trabalhos que definem as crianças como atores sociais e a infância como entidade ou instituição construída do ponto de vista social. Estes trabalhos iniciam-se na década de 1970 e proliferam e são sistematizados na década de 1990 (PROUT, s/d). 
interesse acadêmico pelo campo que emergia; a criação de revistas especializadas, tal como a Childhood (1993), publicada pela editora Sage tornando-se lócus das contribuições de todo o mundo sobre a área; a realização de congressos e simpósios internacionais, como o Congresso Mundial de Sociologia de 1990, em que um grupo de sociólogos da infância se reúne pela primeira vez. Já nos países de língua francesa, há a publicação de um número da Revue de l'Institut de Sociologie de Bruxelles, intitulado "Infância e Ciências Sociais", produto do seminário do grupo de pesquisa internacional "Modos de vida de crianças", em 1990; a criação do comitê na Associação Internacional de Sociólogos de Língua Francesa, também interessado na infância ; a relação com a École dês Hautes Étues em Sciences Sociales, através do seminário "Infância e Política: tentativa de construção do objeto" (1993); e com o Institut National d'Études Démographiques, através do colóquio "A criança na família, vinte anos de mudanças" (1994).

Por sua vez, os sociólogos da educação, na ocasião do colóquio "Por um novo balanço da sociologia da educação", em 1993, destinado a atualizar a evolução do campo formam uma comissão "Sociologia da infância", onde se pode observar a passagem de estudos sociodemográficos aos estudos etnográficos, no âmbito de uma socioantropologia da infância. Tendem a revelar a criança, e não mais simplesmente o aluno, mas enquanto ator social no quadro de uma desescolarização da sociologia da educação (SIROTA, p. 11, 2001).

A revista científica Cadernos de Pesquisa da Fundação Carlos Chagas - SP, traduz em 2001 dois dos principais artigos que sintetizam o boom da produção européia, publicados pela Revista Éducation et Sociétés de 1998 a 1999 (QUINTEIRO, 2003). Ambos artigos são breves estados da arte das produções de língua francesa e inglesa, que, segundo Sarmento (2008), em suas abordagens de Sociologia da Infância são devedoras das contribuições da historiografia contemporânea de infância. Vale lembrar que a Itália tem uma larga experiência de pesquisa e publicações que contemplam as crianças como atores sociais e protagonistas de suas pesquisas, mas que não designaram de Sociologia da Infância.

Em "Sociologia da Infância: balanço dos trabalhos de língua inglesa" de Cléopâtre Montandon (2001), os trabalhos de pesquisa são marcados pela "predominância do empírico" e pela diversidade de questões, dada as diferentes proveniências disciplinares dos pesquisadores anglo-saxões, como economia, demografia, sociologia 
geral, biológica, saúde e a área dos estudos feministas (SARMENTO, 2008), e abrangendo várias áreas do mundo social das crianças, como: família, políticas públicas, cultura de pares, identidades sociais, mídias e indústria cultural, contextos de lazer, espaços urbanos e o corpo. As diversas pesquisas afiliam-se em diferentes abordagens teóricas, e as escolhas metodológicas mais destacadas foram: pesquisas comparativas e longitudinais, etnográficas, quantitativas, pesquisa ação e pesquisa intervenção, todas buscando tornar as crianças foco das investigações. A autora classifica tais estudos dentro de quatro categorias: as que estudam relações entre as gerações; relações entre as crianças; as que abordam as crianças como grupo de idade e as que examinam os diferentes dispositivos institucionais dirigidos às crianças. $O$ que chamou atenção neste balanço das produções foi: a pouca aparição das instituições escolares e das práticas sociais das crianças nas escolas; a influencia do interacionismo simbólico nas pesquisas de origem americana; da forte institucionalização do campo e a grande presença as pesquisas escandinavas.

Régine Sirota (2001), em "Emergência de uma Sociologia da Infância: a evolução do objeto e do olhar", demonstra que, ao contrário da produção de língua inglesa, as pesquisas francofônicas são predominantemente marcadas pelos dispositivos institucionais, família, justiça e principalmente a escola. Essa corrente se caracteriza por um diálogo crítico com a Sociologia Geral e um predomínio dos estudos sobre as práticas sociais das crianças francesas, o que dá aos estudos dessa origem um toque de particularidade cultural. As pesquisas são sobre temáticas como os rituais infantis e as festas, os jogos e brincadeiras, as práticas sociais na escola e as relações de amizade. Também cabe um destaque da relação entre a Sociologia da Infância francesa e a Sociologia da Educação, que desvelou a criança como ator social anterior à sua condição de aluno. Ao olhar para a criança pequena através da escola maternal, com a pesquisa pioneira - que não ganha muito destaque nesse levantamento - chamada o "Ofício de Criança" (CHAMBOREDON e PRÉVOT, 1986), se discute as condições sociais da descoberta da primeira infância como objeto pedagógico e as funções sociais que a instituição escolar pode preencher baseada na definição de primeira infância.

Fora as referências de balanço da produção ou de estado da arte da Sociologia da Infância, reapresentadas aqui, ressaltam-se pesquisas 
individuais de grande influência no cenário brasileiro ou que podem contribuir com a análise da realidade brasileira.

Para os estudiosos da Sociologia da Infância que atuam na área da Educação Infantil, cabe um aprofundamento no artigo de Eric Plaisance (2004), "Por uma sociologia da pequena infância", que além de debater acerca da sociologia da pequena infância ser analisada como sociologia da socialização, a partir dos modelos: um vertical de imposição de normas, valores e práticas (o modelo durkheimiano), e o modelo interativo da construção de si por meio de "negociação" entre a criança e o seu meio - analisa a escolarização precoce com o caso da escola maternal na França, por meio da evolução da frequência e do currículo. Problematiza a interrogação sobre qual é ofício de aluno na escola maternal; aborda o currículo, entendendo-o ao mesmo tempo como currículo formal (prescrito oficialmente), mas não como programa institucional e como currículo real (conjunto das experiências das crianças nas situações cotidianas). Fala sobre cultura nas suas diferentes dimensões e sobre a importância dos diálogos interdisciplinares para a fecundidade da área.

No sentido de somar com contribuições para a consolidação do campo, o sociólogo americano William Corsaro é internacionalmente conhecido por estudar as interações de pares, por meio da qual, segundo ele, as crianças constroem processos de subjetivação na construção simbólica dos seus modos de vida, estabelecendo interações que as levam a reproduzirem interpretativamente as culturas sociétais e a recriá-las, e não apenas imitá-las. Inspirado na idéia de "estruturação" de A. Giddens, Corsaro substitui o conceito de socialização clássico pelo de reprodução interpretativa, cuja tese principal é de que as crianças não apenas recebem do mundo adulto uma cultura pronta sobre a forma de crenças, valores e conhecimentos. Ao invés de serem incorporadas passivamente em forma de saberes e comportamentos, são transformados gerando juízos e condutas infantis de forma a atender seus interesses próprios enquanto crianças (CORSARO, 2009), mostrando que elas operam mudanças na cultura, seja sob a forma como a integram e interpretam, seja nos efeitos que produzem a partir de suas práticas, ou seja, elas também intervêm junto aos adultos. Assim, essa capacidade de reinterpretar e transformar a herança cultural transmitida pelas gerações anteriores é concebida como a construção de uma cultura específica - as culturas infantis, foco da Sociologia da Infância. 
Ele mostrou [...] que quando as crianças interagem representando papéis, dando porém livre curso à imaginação, por um lado tentam adquirir um maior controle sobre suas vidas e por outro compartilham esse controle entre si. Corsaro realizou etnografia comparativa na Itália e sobretudo nos Estados Unidos a fim de examinar como a participação das crianças nas brincadeiras de faz-de-conta contribui para a produção e a extensão da cultura de pares [...] Ele é um dos promotores de uma perspectiva interpretativa e construtivista para estudar a socialização das crianças. Segundo essa abordagem, a socialização das crianças não é uma questão de adaptação nem de interiorização, mas um processo de apropriação, de inovação e de reprodução (MONTANDON, 2001, p. 7).

Aproximando mais da paisagem científica de além mar, falase agora da Sociologia da Infância no contexto de Portugal, que dada a "familiaridade" linguística, encontra grande aceitação em terras brasileiras, arregimentando grande número de nossos pesquisadoras e pesquisadores. O lócus que reúne ex-colonizadores e ex-colonizados é o Instituto de Estudo da Criança - IEC da Universidade do Minho em Braga, tendo na figura do prof. Manuel Jacinto Sarmento seu maior interlocutor, em suas próprias palavras, diz, mantemos um "diálogo intenso com os estudos da infância do Brasil, testemunhado pela produção conjunta" (2008, p.17). Ele é conhecido, por sua sistematização da teórica da Sociologia da Infância (2008), pela conceituação e problematização do conceito de geração, e pela diferenciação entre infância e crianças (2005); discorre sobre as culturas infantis; sobre a cidadania ativa na infância; sobre as imagens sociais e científicas da infância, destacando a invisibilidade, ocultamento e as negatividades pejorativas criadas sobre a infância (2007); além de ter entrada no campo metodológico por tematizar a pesquisa etnográfica (2003); entre outras publicações portuguesas que aqui aportam.

Tal intercâmbio tem hibridizado os contextos de pesquisa, aproximando-os sem os marcadores de distinção necessários para cenários sócio-culturais tão díspares, a exemplo da não oferta de creche em Portugal e da diferença quantitativa da população infantil nos dois países, e no contexto europeu como um todo; o que de forma nenhuma retira a relevância das parcerias firmadas e da contribuição do grupo de pesquisadoras e pesquisadores portugueses com a área, principalmente 
devido à aproximação dos estudos da infância de Portugal com a Sociologia da Juventude e a Sociologia da Família, e a sua articulação com as políticas públicas. Lembra-se apenas da necessidade de se relativizar a distinção dos contextos sociais, culturais, políticos e econômicos, que podem ser esquecidos por "parecer" que falamos a "mesma" língua.

Com a finalidade de sistematizar as pesquisas da área por afinidades conceituais, temáticas e metodológicas, de uma forma geral, as pesquisas filiadas à Sociologia da Infância podem ser divididas em três grandes enfoques ou abordagens, conforme sociólogo e socióloga alemães Heinz Hengt e Helga Zeiher ${ }^{6}$, na versão italiana do livro Per una Nuova Sociologia dell'Infazia (2004) ${ }^{7}$, o que representa um ganho para a área, por permitir distinguir os fundamentos teóricos metodológicos e propiciar filiações teóricas. As abordagens são:

i) sociologia interpretativa da infância: abordagem microssociológica e etnográfica - toma como ponto de partida a idéia de que as crianças merecem ser estudadas por si mesmas e de suas próprias perspectivas, suas condições de vida, atividades, relações, conhecimentos e experiências, valorizam seu agir autônomo e sua criatividade. Os trabalhos empíricos têm como metodologia predominante as pesquisas etnográficas, derivadas da Antropologia. São temas que privilegiam as interações intra e intergeracional; as culturas infantis, a ação social das crianças, os jogos, brincadeiras e a cultura lúdica, as crianças e as mídias, relações de gênero;

ii) sociologia desconstrucionista da infância - as concepções de criança e infância são tratadas como formações discursivas socialmente construídas, através das quais as ideias, imagense conhecimento sobre as crianças e infância se comunicam com a vida social. Nessa abordagem, três conceitos, por vezes, são usados como sinônimos: construcionismo ou construtivismo social, desconstrucionismo e análise do discurso. E tem em

6 A autora realizou pesquisa sobre a utilização do tempo pelas crianças fora das escolas, enfatizando a importância da estrutura do mundo cotidiano para organização e vivencia do tempo da/na infância, que vão dos órgãos públicos e suas políticas para a faixa etária e o papel dos pais nos contextos de vida urbana, possibilitando através dessa pesquisa realizada em bairros de Berlim, a reflexão entre indivíduo - infantil e sociedade -, e entre ação individual infantil e estruturas sociais (2004).

7 Aqui se trata de uma tradução feita por membros do grupo de pesquisa - GEPEDISC, com complementações minhas. Dada a importância desta publicação para os estudos e compreensão deste novo campo, sua tradução se faz imprensindível. 
Michel Foucault a principal fonte de inspiração, dada sua defesa de que os discursos são indissociáveis da prática social e das instituições que as constituem. Essa linha tenta tornar visível, por meio da análise de discurso, a ideologia que os discursos veiculam, através de estratégias de retórica;

iii) sociologia estrutural da infância - não deve ser confundida com o "estruturalismo" ou "estruturalismo-funcionalista". A infância é tida como elemento permanente e como uma parte da estrutura social das sociedades modernas, mas também como uma estrutura em si mesma, comparada à classe ou a gênero. Como categoria social permanente na sociedade, seus membros mudam, mas a infância e suas relações com as outras gerações continuam, sendo um componente essencial da ordem social. Esta linha põe em relevo as condições estruturais em que a infância se situa, e em que ocorrem as suas possibilidades de ação. Tem uma perspectiva predominantemente macrossociológica, considerando condições socioeconômicas, estatuto político, sentidos de identidade, indicadores demográficos, econômicos e sociais, e de que modo essas relações afetam as estruturas sociais. Ao defender a infância como parte constitutiva da sociedade, desvela as marginalizações das crianças, insistindo na posição social, política, jurídica, cultural e ideológica delas, a qual é determinada em relação à divisão de poder, trabalho, recursos econômicos, espaciais e temporais entre as gerações no conjunto da sociedade. $O$ foco deste tipo de pesquisa não é a criança e a infância em si, mas sim o modo com que as crianças são integradas nas estruturas sociais em que vivem. As crianças são consideradas como atores, sujeitos, porém não interessa o comportamento individual, mas sim o lugar que ocupa a atividade das crianças enquanto grupo da população em relação à reprodução da divisão do trabalho, assim como está organizada pela sociedade.

Dando prosseguimento, para encerrar esta apresentação, Prout (s/d) diz serem necessárias novas reflexões e renovações do/no campo. Para ele “Parece que depois de duas décadas de tão extraordinário esforço criativo, o qual por sua vez deu origem a novas ideias de caráter teórico, metodológico e empírico, a nova Sociologia da Infância se apresenta 
cada vez mais perturbada". Ele caracteriza como maior problema o fato da Sociologia da Infância ter buscado ocupar um espaço dentro da Sociologia moderna nos seus próprios termos, ou seja, em meio à sua crise, no conjunto das dicotomias, haja vista a Sociologia ter dificuldades de lidar com o instável mundo da modernidade tardia, cabendo à Sociologia da Infância, segundo ele, alçar o "degrau da modernidade" ou pós-modernidade?

\begin{abstract}
A Sociologia da Infância contemporânea deu os primeiros passos neste período em que a vida social assumia um caráter diferente e a teoria social enfrentava uma difícil crise. Começou por estar associada a uma tradição sociológica e a um aparato teórico que haviam já entrado num período de dúvida, instabilidade e reproblematização. Nas décadas de 1980 e 1990, a Sociologia tentava manter-se a par de um complexo conjunto de mudanças sociais anteriores delineadas e que abalaram os pressupostos modernos que the haviam servido de base durante quase todo o século anterior. O problema era que a teoria social moderna nunca havia proporcionado muito espaço à infância. A Sociologia da Infância via-se, por essa razão, a braços com uma dupla missão; criar espaço para a infância no discurso sociológico e confrontar a complexidade e ambigüidade da infância enquanto fenômeno contemporâneo e instável (PROUT, s/d, p. 4).
\end{abstract}

Para uma maior problematização da crítica do autor à Sociologia da Infância, seria necessário um aprofundamento teórico acerca do que ele denomina de Sociologia na modernidade tardia, o que não coube ao perímetro deste estudo, mas que é possível ser feito em pesquisas que deverão nascer, visto ser esse um campo repleto de possibilidades investigativas.

\title{
Palavras finais: para não concluir
}

Quando nos referimos à compreensão das crianças e suas infâncias pelo viés sociológico somos remetidas às discussões do campo da sociologia da infância, debate esse profícuo que encontra na atualidade muitos interlocutores, e que, pelas contribuições que apresenta e por seu caráter inovador acaba ganhando certa hegemonia teórico-metodológica dentro da área, levando pesquisadores e pesquisadoras a repetição muito mais do que a produção/criação. 
Os estudos traduzidos que chegam até nós demonstram o percurso de consolidação da área ou o estado do campo além mar, pois, internacionalmente, muitas pesquisas têm sido produzidas, mas só o que se encontra legitimamente aceito pelo campo ganha larga divulgação. No entanto, precisamos relativizar tais estudos, assim como toda teoria importada, ainda mais com o retorno das discussões sobre as diferentes formas de colonialismo.

É importante dizer que quando uma nova área do conhecimento se cria, evidente que ao mesmo tempo em que se abre um novo campo, novas possibilidades, também se criam novas hierarquias, novas inscrições, aqueles que sabem os que não sabem, aqueles que pertencem e não ao campo, as associações mundiais, os congressos e a luta pela redistribuição de recursos financeiros. Uma nova área, em geral, disputa financiamentos com as áreas consagradas, isto vale por aqui também (ABRAMOWICZ, 2010, p. 4).

As pesquisas sobre e com a pequena infância, trazem a tensão entre as diferentes correntes teórico-metodológicas, buscando situar neste exercício de superação constante das amarras do pensamento único, determinado, positivista tão potente e enraizado em nossas consciências acadêmicas, repletas de armadilhas em suas normas; as trilhas epistemológicas e políticas utilizadas pelos sociólogos das infâncias na busca pela compreensão do seu objeto.

O que pode nos interessar na Sociologia da Infância, é o que nos ajuda a pensar a criança, não é só pela maleta de instrumentos teóricos ou novidades de pesquisa que ela trouxe ao cunhar o que é infância com os conceitos de cultura infantil, protagonismo, autoria social, processos de socialização, mas no nosso entender, o que é interessante aproveitar a processualidade na qual ela viveu ao se constituir como um campo teórico em um terreno tão cristalizado como o campo científico francês, em especial o da sociologia e o da educação (ABRAMOWICZ, 2010, p.5).

Não é fácil organizar um quadro que permita tentar interpretar pontos de vista sociológicos tão diversos. Espero ter conseguido demonstrar, com esta breve cartografia, que o emergente campo da Sociologia da Infância pode se fundamentar em diferentes escolas sociológicas, e que temos que nos preocupar com o possível isolamento teórico desse novo campo, caso não promovamos o diálogo entre a Sociologia da Infância e a Sociologia, tão necessário para o amadurecimento do campo. 
Apesar da Sociologia Brasileira da Infância manter uma agenda de pesquisa profícua e diversificada, insisto na necessidade de uma revisão ou renovação no sentido contrário do que propõem as críticas de Prout (s/d), ou seja, na urgência em revisitarmos as teorias sociológicas modernas, haja vista, a meu ver, termos passado (pedagogas e pedagogos, cientistas sociais, docentes da educação infantil, formuladores de políticas públicas para a infância) muito apressadamente da total desconsideração da criança como ator social e agente de direitos, para seu protagonismo e investigação de seus mundos, descolando eles os mundos - da realidade social, ou da estrutura social nas quais essas crianças estão inseridas. Sem abusar dos generalismos, é certo que há pesquisas que, mesmo dedicando-se ao microssocial, a análises interpretativas ou do discurso, contemplam ou inserem as crianças e suas pesquisas em seu contexto sociopolítico-econômico-cultural da realidade nacional, mas poucas são as pesquisas que se dedicaram à investigação e análises na perspectiva macrossociológica da infância, e menos ainda, as que se propuseram à construção teórica de uma sociologia estrutural da infância brasileira.

Por isso há de se considerar que,

[...] o sociólogo que estuda o Brasil não sabe mais que sistema de conceitos utilizar. Todas as noções que aprendeu nos países europeus ou norteamericanos não valem aqui. O antigo mistura-se com o novo. As épocas históricas emaranham-se umas nas outras. Os mesmos termos como "classe social" ou "dialética histórica" não têm o mesmo significado, não recobrem as mesmas realidades concretas. Seria necessário, em lugar de conceitos, descobrir noções de certo modo líquidas, capazes de descrever fenômenos de fusão, de ebulição, de interpenetração, noções que se modelariam conforme uma realidade viva, em perpétua transformação. O sociólogo que quiser compreender o Brasil não raro precisa transformar-se em poeta (BASTIDE, 1976, p.15)

\section{Referências}

ABRAMOWICZ, Anete A pesquisa com crianças em infâncias: perspectivas metodológicas. II GRUPECI. Rio de Janeiro: Universidade Estadual do Rio de Janeiro, 2010. (mimeo.). 
BASTIDE, Roger. Introdução. In: Brasil Terra de Contrastes. 4.ed. São Paulo: Difusão Européia do Livro, 1976. p. 9-15.

BELLONI, Maria Luiza. 0 que é a sociologia da infância? Campinas: Autores Associados, 2009.

BLUMER, Herbet. Symbolic Interactionism. Englewood Cliffs: PrenticeHall, 1969.

BOURDIEU, Pierre. A Economia das Trocas Simbólicas, 5. ed. São Paulo: Perspectiva, 2004.

. Campo Intelectual e Projeto Criador. In: POUILLON. J. (org.) Problemas do Estruturalismo. Rio de Janeiro: Zahar, 1968. p. 17- 38.

CANAVIEIRA, Fabiana O. A Educação Infantil no olho do furacão: o movimento político e as contribuições da Sociologia da Infância. Dissertação (Mestrado). Faculdade de Educação/UNICAMP, Campinas, 2010.

CHAMBOREDON, Jean C. e PREVOT, Jean. O "ofício de criança": definição social da primeira infância e funções diferenciadas da escola materna. Cadernos de Pesquisa. São Paulo: Fundação Carlos Chagas; São Paulo: Cortez Editora, n. 59, p. 32-56, nov. 1986.

CORSARO. William. Reprodução Interpretativa e Cultura de Pares. In: MULLER, Fernanda; CARVALHO, Ana Maria. (orgs.). Teoria e Prática na Pesquisa com Crianças: diálogos com Wiilliam Corsaro. São Paulo: Cortez, 2009. p. 31-50.

DAHLBERG, Gunila; MOSS, Peter; PENCE, Alan. Qualidade na educação da primeira infância: perspectivas pós-modernas. Porto Alegre: Artmed, 2003.

DIAS, Lara S. Infância nas brincadeiras: um estudo em creches públicas e privadas de Campinas. Dissertação (Mestrado). Faculdade de Educação/UNICAMP. Campinas, 2005.

DUBAR, Claude. A Socialização: construção das identidades sociais e profissionais. Porto: Porto Editora, 1997.

DURKHEIM, Émile. Educação e Sociedade. 11. ed. São Paulo: Melhoramento; Rio de Janeiro: Fundação Nacional de Material Escolar, 1978. 
FARIA, Ana Lúcia G. de; DEMARTINI, Zélia de Brito Fabri; PRADO, Patrícia Dias (orgs.). Por uma cultura da infância: metodologia de pesquisa com crianças. Campinas (SP): Autores Associados, 2002.

FARIA, Ana Lúcia Goulart de. O espaço físico como um dos elementos fundamentais para uma pedagogia da educação infantil. In: FARIA, Ana Lúcia Goulart de, PALHARES, Marina Silveira (org.). Educação infantil pós-LDB: rumos e desafios. Campinas, São Paulo: Autores Associados, 2005.

FLORESTAN, Fernandes. Folclore e mudança social na cidade de São Paulo, $3^{\circ}$.ed. São Paulo: Martins Fontes, 2004.

HENGST, Heinz e ZEIHER, Helga. Per una sociologia dell'infanzia. Milão: Franco Angeli, 2004.

IANNI. Octavio. Sociologia da Sociologia Latino-America. 2. ed. Rio de Janeiro: Civilização Brasileira, 1976.

KONDER, Leandro. Marx e a Sociologia da Educação. In:TURA, Ma de L. R. (org.). Sociologia para educadores. 4. ed. Rio de Janeiro: Quartet, 2006. p. 11-23.

MANNHEIM, Karl. Ideologia e Utopia. Rio de Janeiro: Zahar Editores, 1968.

Funções das gerações novas. In: PEREIRA, L; FORACCH, I, M. M. Educação e Sociedade. São Paulo: Companhia Editora Nacional, 1976. p. 91-97.

MARCHI, Rita de Cássia. As Teorias da Socialização e o Novo Paradigma para os Estudos Sociais da Infância. Educação e Realidade, Porto Alegre, v. 34, n. 1, p. 227-246, jan/abr 2009.

MONTANDON, Cleopatre. Sociologia da infância: balanço dos trabalhos em língua inglesa. Cadernos de Pesquisa, São Paulo, n.112, p.33-60, 2001.

MÜLLER, Fernanda. Socialização na escola: transições, aprendizagem e amizade na visão das crianças. Educar em Revista, n. 32. Curitiba: UFPR, 2008.

NOSELLA, Paolo. A linha vermelha do planeta infância: o socialismo e a educação da criança. In: FREITAS, Marcos Cezar de; KULHMANN Jr., 
Moysés (orgs.). Os intelectuais na história da infância. São Paulo: Cortez, 2002. p. 129 - 166.

PAIS, José Machado. Culturas juvenis. Lisboa: Imprensa Nacional Casa da Moeda, 1993.

PINTO, Manuel. A infância como construção social. In: PINTO, Manuel; SARMENTO, Manuel Jacinto (org.). As Crianças: contextos e identidades. Portugal: Universidade do Minho/Centro de Estudos da Criança, 1997. p. 33-73.

PLAISANCE, Eric. Para uma sociologia da pequena infância. Educação e sociedade. Campinas, n. 86, p. 219-242, 2004.

PROUT. Alan. Reconsiderar a Nova Sociologia da Infância. (s/d). (mineo).

QUINTEIRO. Jucirema. Sobre a emergência de uma sociologia da infância: contribuições para o debate. Perspectiva, Florianópolis, v.20, especial, p.137-163, 2003.

SARACENO, Chiara. Sociologia da família. Lisboa: Estampa, 1997.

SARMENTO, Jacinto Manuel. Sociologia da Infância: correntes e confluências. In: SARMENTO, M. e GOUVEA, M. Cristina S. de. (orgs.). Estudos da Infância: Educação e Práticas Sociais. Petrópolis (RJ): Vozes, 2008. p. 17-38.

SIROTA, Regine. Emergência de uma sociologia da infância: evolução do objeto e do olhar. Cadernos de Pesquisa, São Paulo, n. 112, p. 7-31. 2001.

Recebido em: outubro/2016

Aprovado em: dezembro/2016 